\title{
KAJIAN LINGKUNGAN HIDUP STRATEGIS (KLHS) KAWASAN PERUNTUKAN PARIWISATA DI KABUPATEN BOLAANG MONGONDOW
}

\author{
Susanti Hadji Ali \\ Bobby J. V. Polii \\ Wiske Ch. Rotinsulu
}

ABSTRACT

This research objectives for (1) indentifying and review priority tourism strategic issues, (2) identifying and analyzing the impacts of RTRW programs for tourism destinations, (3) reviewing efforts to minimize the negative impacts that will occur as a result of the implementation of plans and programs in tourism destinations in Bolaang Mongondow ditricts. The research was conducted in Bolaang Mongondow Regency of North Sulawesi Province, from September to October 2017. This method uses is straight observation on purposive sampling with semi detailed method based on field observation and Foccus Group Disscusion (FGD). The strategic environmental review is undertaken through several stages by identifying priority strategic issues, analyzing data to illustrate, assessing the impact of policies, plans and programmes and finally produce the formula in mitigation \& recommendation steps. The sources of the data obtained are primary data contributed by interviews with important key informants and implementation of FGD. The research cobducts to the results which are priority strategic issues identified during the study, include biodiversity, waste, safety and comfort, welfare improvement, mangrove damage and coral reefs. The implementation of the 20 years program defined in the Bolaang Mongondow RTRW regulation is the award winning tour of hot water bath development, three island and white sand strategic development of horticulture impact on biodiversity, waste, security and comfort, welfare improvement, mangrove damage and coral reefs. Mitigations measures to minimize impacts are to produce Regulations and Sosialization in reducing tourism actifities in order to avoid biodiversity degradation, to create solid waste disposal facilities and waste water reservoirs, to conduct a well, manage security officers around tourism areas, to produce Regulation in maintaining tourism area during their actifities on diving and coastal recreation. The whole regulation and actions plans finally conducts to well and health environment for mangrove and coral reef ecosystem. The program on designation in Bolaang Mongondow Regency is can have negative impact to biodiversity, waste, security and comfort, mangrove damage and coral reefs. Positif impact is increased welfare. The positive impact from real program is increased welfare. In order to minimize negative impacts of the Program policies, the result of the study can also be recommended for Bolaang Mongondow regency to be applied or able to implement mitigation measures to minimize negatif impacts in the future time.

Keywords: $\quad$ strategic environmental assessment (KLHS), regional spatial planning, tourism designation area, Bolaang Mongondow Regency

\section{ABSTRAK}

Penelitian ini bertujuan untuk (1) mengidentifikasi dan mengkaji isu-isu strategis prioritas bidang pariwisata, (2) mengidentifikasi mengkaji dan menganalisis dampak rencana dan program RTRW kawasan peruntukan pariwisata, (3) mengkaji upayaupaya meminimalkan dampak negatif yang akan terjadi akibat dari pelaksanaan Program pada kawasan peruntukan pariwisata di Kabupaten Bolaang Mongondow. Penelitian dilaksanakan di Kabupaten Bolaang Mongondow Provinsi Sulawesi Utara, sejak bulan September sampai dengan Oktober 2017. Penelitian ini menggunakan observasi langsung dengan teknik purposive sampling dengan metode semi detil berdasarkan pengamatan di lapangan dan melalui Focus Group Disscusion (FGD) serta wawancara dengan berbagai informan kunci. Kajian lingkungan hidup strategis dilakukan melalui beberapa tahap yaitu identifikasi isu strategis prioritas, analisis data untuk menggambarkan masalah-masalah strategis, penilaian dampak program, perumusan langkah-langkah mitigasi. Hasil penelitian menunjukkan bahwa isu strategis prioritas diidentifikasi dalam penelitian meliputi keanekaragaman hayati, limbah, terganggunya keamanan dan kenyamanan, peningkatan kesejahteraan, kerusakan mangrove dan terumbu karang. Pelaksanaan program selama 20 tahun yang termuat dalam perda RTRW Perda No 2 Tahun 2014, Kawasan peruntukan pariwisata Kabupaten Bolaang Mongondow meliputi: kawasan peruntukan pariwisata budaya dan alam. Kawasan peruntukan pariwisata budaya berupa Makam Bogani di Kecamatan Passi Barat, Kecamatan Passi Timur, Kecamatan Bilalang dan seluruh kecamatan yang memiliki situs-situs sejarah. Kawasan peruntukan pariwisata alam meliputi: wisata petualang dan ilmu pengetahuan di Taman Nasional Bogani Nani Wartabone, tempat pemandian air panas Bakan, wisata pendakian Gunung Ambang, pantai Lolan, air terjun Otam dan tempat pemandian di pantai Tanjung Ompu, Pulau Molosing serta Kawasan Pulau Tiga membawa dampak terhadap keanekaragaman hayati, limbah, keamanan dan kenyamanan, peningkatan kesejahteraan, kerusakan mangrove dan terumbu karang. Langkah-langkah mitigasi untuk meminimalkan dampak yaitu dengan membuat peraturan dan sosialisasi sebagai faktor pembatas kegiatan pariwisata agar tidak terjadi kerusakan keanekaragaman hayati, menyiapkan fasilitas penampungan dan pengolahan limbah padat dan cair, menyiapkan petugas keamanan dan tim badan penanggulangan bencana di sekitar kawasan pariwisata, membuat peraturan sebagai batasan untuk kegiatan wisata penyelaman dan wisata pesisir agar tidak terjadi kerusakan mangrove dan terumbu karang. Penelitian menyimpulkan bahwa program pengembangan kawasan peruntukan pariwisata di Kabupaten Bolaang Mongondow dapat berpotensi menimbulkan dampak negatif terhadap keanekaragaman hayati, limbah, keamanan dan kenyamanan, kerusakan mangrove dan terumbu karang . Dampak positif pelaksanaan program yang di timbulkan adalah peningkatan kesejahteraan masyarakat karena terbukanya peluang usaha di sekitar kawasan pariwisata. Untuk dapat meminimalkan dampak negatif dari pelaksanaan program disarankan agar Pemerintah Kabupaten Bolaang Mongondow dapat menerapkan langkah-langkah mitigasi untuk meminimalisir dampak.

Kata kunci: kajian lingkungan hidup strategis (KLHS), Rencana Tata Ruang Wilayah (RTRW), kawasan peruntukan pariwisata, Kabupaten Bolaang Mongondow 


\section{PENDAHULUAN}

\section{Latar Belakang}

Pemerintah Kabupaten Bolaang Mongondow telah menetapkan Peraturan Daerah No 02 Tahun 2014-2034 tentang Rencana Tata Ruang Wilayah. Kawasan peruntukan pariwisata di Kabupaten Bolaang Mongondow meliputi wilayah yang memiliki potensi sumber daya alam dan budaya. Pengembangan kawasan peruntukan pariwisata di Bolaang Mongondow akan membawa dampak negatif terhadap sumber daya alam dan lingkungan sekitar. Oleh karena itu pada tahapan perencanaan pengembangan Pemerintah Kabupaten Bolaang Mongondow harus melakukan Kajian Lingkungan Hidup Strategis untuk melihat apakah dalam kebijakan, rencana dan program telah memasukkan pertimbangan lingkungan guna Pembangunan berkelanjutan.

\section{Rumusan Masalah}

1. Apakah isu-isu strategis prioritas dalam pelaksanaan Program Pariwisata di Kabupaten Bolaang Mongondow?

2. Apakah dampak yang di timbulkan dari pelaksanaan Program Rencana Tata Ruang Wilayah (RTRW) kawasan peruntukan Pariwisata di Kabupaten Bolaang Mongondow?

3. Bagaimana upaya meminimalkan dampak negatif yang akan terjadi akibat dari pelaksanaan Program pada kawasan peruntukan pariwisata di Kabupaten Bolaang Mongondow?

\section{Tujuan Penelitian}

1. Mengidentifikasi dan mengkaji isu-isu strategis prioritas bidang pariwisata di Kabupaten Bolaang Mongondow.

2. Mengidentifikasi, mengkaji dan menganalisis dampak Program RTRW kawasan peruntukan pariwisata di Kabupaten Bolaang Mongondow terhadap lingkungan.

3. Mengkaji upaya-upaya meminimalkan dampak negatif yang akan terjadi akibat dari pelaksanaan Program pada kawasan peruntukan pariwisata di Kabupaten Bolaang Mongondow.

\section{Manfaat Penelitian}

Diharapkan dari hasil penelitian ini dapat memberikan manfaat, antara lain:

1. Memberi masukan kepada Pemerintah Daerah dalam pengambilan keputusan terhadap pengelolaan Sumber day alam dan pariwisata untuk memanfaatkan prinsip-prinsip KLHS.
2. Memberi informasi kepada Pemerintah Daerah tentang pentingnya KLHS dalam RTRW, RPJMD dan RPJPD agar prinsip pembangunan berkelanjutan menjadi dasar dalam pembangunan suatu wilayah.

3. Memberi pandangan kepada masyarakat tentang pentingnya penyelenggaraan KLHS untuk meminimalkan dampak negative terhadap lingkungan guna pembangunan berkelanjutan.

\section{Kajian Lingkungan Hidup Strategis (KLHS)}

Kajian Lingkungan Hidup Strategis (KLHS) merupakan salah satu produk penting modernisasi ekologi Tahun 1990 sebagai suatu institusi baru yang dibentuk untuk memperbaiki politik dan tata kelola lingkungan hidup, dengan fokus utama mengintegrasikan pertimbangan lingkungan pada tingkat pengambilan keputusan yang bersifat strategis, yakni pada tahap kebijakan, rencana dan program pembangunan, namun agar semangat KLHS ini dapat diselami dengan baik, maka dihadirkan suatu buku yang menghimpun secara komprehensif berbagai konsep tentang KLHS.

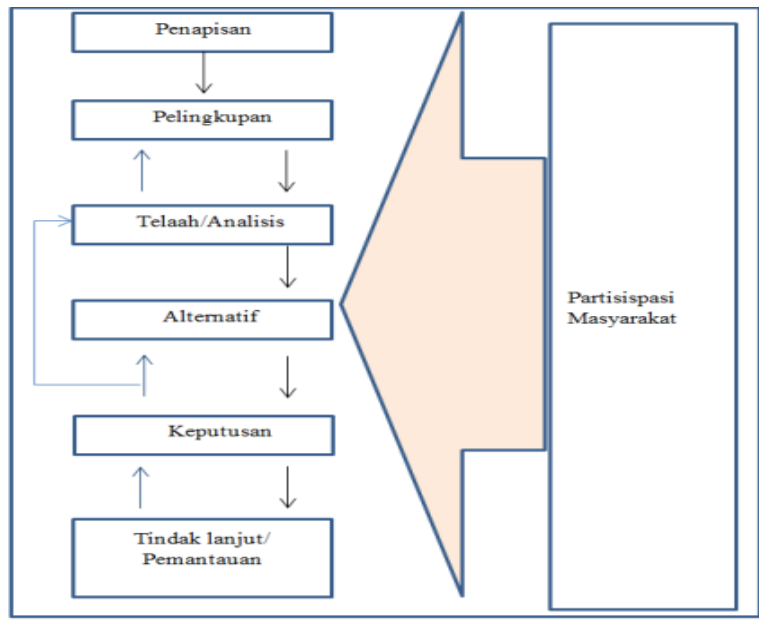

Gambar 1. Kerangka Kerja KLHS menurut Permen LH No 9 Tahun 2011

\section{Definisi Pariwisata}

Menurut Saputri (Jurnal Tahun 2012), Pari berarti berkeliling atau bersama dan wisata adalah perjalanan, jadi secara pengertiannya pariwisata berarti perjalaanan keliling dari suatu tempat ke tempat lain. Kepariwisataan adalah merupakan kegiatan jasa yang memanfaatkan kekayaan alam dan lingkungan hidup yang khas seperti: hasil budaya, peninggalan sejarah, pemandangan alam yang indah dan iklim yang nyaman.

Kepariwisataan adalah keseluruhan kegiatan yang terkait dengan pariwisata dan bersifat multidimensi serta multidisiplin yang muncul 
sebagai wujud kebutuhan setiap orang dan negara serta interaksi antara wisatawan dan masyarakat setempat, sesama wisatawan, Pemerintah, Pemerintah Daerah dan pengusaha. Daya Tarik Wisata adalah segala sesuatu yang memiliki keunikan, keindahan dan nilai yang berupa keanekaragaman kekayaan alam, budaya dan hasil buatan manusia yang menjadi sasaran atau tujuan kunjungan wisatawan.

Dampak positif dari Pariwisata:

1. Pariwisata dapat merangsang pertumbuhan pengawasan dan langkah-langkah terapan untuk perlindungan lingkungan dan atau lansekap dan atau satwa liar.

2. Pariwisata dapat membantu memperkenalkan keberadaan kawasan Taman Nasional dan wilayah Konservasi.

3. Pariwisata dapat memperkenalkan dan mempromosikan keberadaan bangunan atau kawasan heritage.

4. Pariwisata dapat mendatangkan profit sebagai sumber pendanaan suatu kawasan.

Dampak negatif dari pariwisata :

1. Wisatawan cenderung membuang sampah/mengotori kawasan wisata.

2. Pariwisata dapat menyebabkan kepadatan baik itu manusia maupun kendaraan.

3. Pariwisata memiliki andil dalam pemcemaran air dan kawasan pantai.

4. Pariwisata dapat menyebabkan erosi.

5. Pariwisata dapat menyebabkan pembangunaan yang tidak di inginkan.

6. Pariwisata dapat menyebabkan kerusakan pada habitat hewan liar.

\section{Kerangka Pemikiran}

Dokumen Rencana Tata Ruang Wilayah (RTRW) merupakan pedoman ruang bagi kegiatan pembangunan di setiap wilayah di Indonesia, sehingga di jadikan sebagai alat kontrol pelaksanaan pembangunan. Kajian Lingkungan Hidup trategis (KLHS) adalah instrument pengelolaan Lingkungan Hidup, merupakan suatu upaya sistematis dan logis dalam memberikan landasan bagi terwujudnya pembangunan berkelanjutan melalui proses pengambilan keputusan yang berwawasan lingkungan.

Pelaksanaan Kajian Lingkungan Hidup Strategis (KLHS) berkenaan dengan Program kawasan peruntukan Pariwisata di Kabupaten Bolaang Mongondow, pola pikir yang melandasi analisis adalah dengan menggunakan teknik Purposive Sampling secara Semi Detail yaitu penilaian berdasar data dan informasi yang akurat dengan mengidentifikasi isu-isu strategis prioritas, mengkaji dampak dari program terhadap kondisi lingkungan hidup di wilayah penelitian, kemudian merumuskan mitigasi dampak dari kebijakan, rencana dan program. Pembangunan kawasan pariwisata menitik beratkan kepada pemantapan pilihan untuk di jadikan basis ekonomi di kawasan tersebut yang akan memberi nilai manfaat bagi masyarakat dan lingkungan lainnya secara optimal. Tujuan pengembangan kawasan pariwisata adalah untuk meningkatkan pendapatan masyarakat, meningkatkan kesempatan kerja dan meningkatkan produktifitas sumber daya manusia.

Perda RTRW belum sepenuhnya menjadi alat pengatur dalam proses pembangunan dan kebijakan penataan ruang belum sepenuhnya memperhatikan kondisi sosial ekonomi serta melibatkan dan mendapat dukungan masyarakat. Tekanan Lingkungan terhadap Rencana Tata Ruang Wilayah (RTRW) seperti penurunan kualitas terhadap daya dukung daya tampung lingkungan dan aktifitas pembangunan menjadikan penataan ruang sebagai bahan pertimbangan untuk arah program kawasan peruntukan pariwisata Kabupaten Bolaang Mongondow Gambar 2.

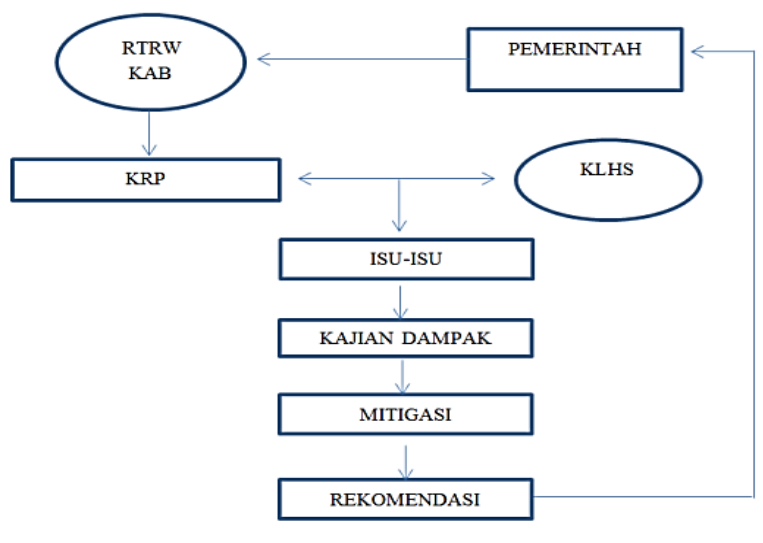

Gambar 2. Kerangka Pemikiran Teoritis

\section{METODOLOGI PENELITIAN}

\section{Lokasi dan Waktu Penelitian}

Penelitian dilaksanakan di Kabupaten Bolaang Mongondow Provinsi Sulawesi Utara, sejak bulan September sampai dengan November 2017.

\section{Metode Penelitian}

Metode pengambilan sampel secara observasi langsung dengan menggunakan teknik purposive sampling. Pengkajian Pengaruh Kebijakan, Rencana dan Program terhadap kondisi Lingkungan 
Hidup.dengan tahapan: melaksanakan indentifikasi dan perumusan isu Pembangunan Berkelanjutan, melaksanakan identifikasi materi muatan Program yang berpotensi menimbulkan pengaruh terhadap kondisi Lingkungan Hidup, menganalisis pengaruh hasil identifikasi dan perumusan. Identifikasi dan perumusan isu Pembangunan Berkelanjutan di lakukan untuk menentukan isu-isu yang paling strategis. Identifikasi dan perumusan isu Pembangunan Berkelanjutan di lakukan dengan menghimpun masukan dari masyarakat dan pemangku kepentingan melalui konsultasi publik. Hasil identifikasi isu Pembangunan Berkelanjutan di rumuskan pioritas dengan mempertimbangkan unsur-unsur: karakteristik wilayah, tingkat pentingnya potensi dampak, keterkaitan antar isu strategis Pembangunan Berkelanjutan keterkaitan dengan muatan Program ,muatan Rencana Perlindungan dan Pengelolaan Lingkungan Hidup, hasil KLHS Program harus di acu serupa dan berada pada wilayah yang berdekatan dan memiliki keterkaitan dan relevansi langsung.

Analisis pengaruh dilakukan dengan memperhatikan hubungan keterkaitan materi muatan Kebijakan, Rencana dan Program dengan isu strategis Pembangunan berkelanjutan hasil konsultasi publik. Hasil analisis memuat kajian: kapasitas daya dukung dan daya tampng Lingkungan Hidup untuk pembangunan, perkiraan dampak dan resiko Lingkungan Hidup, kinerja layanan atau jasa ekosistem, intensitas dan cakupan wilayah bencana alam, status mutu dan ketersediaan sumber daya alam, ketahanan dan potensi keanekaragaman hayati.

Alternatif penyempurnaan Kebijakan, Rencana dan Program: perubahan tujuan dan target, perubahan strategi perencanaan target, perubahan atau penyesuaian ukuran, skala dan lokasi yang lebih memenuhi pertimbangan Pembangunan Berkelanjutan, perubahan atau penyesuaian proses, metode dan adaptasi terhadap perkembangan ilmu pengetahuan dan teknologi yang lebih memenuhi pertimbangan Pembangunan Berkelanjutan. Hasil perumusan alternatif penyempurnaan Program dijadikan dasar dalam menyusun rekomendasi perbaikan untuk pengambilan keputusan Kebijakan, Rencana dan Program yang mengintegrasikan prinsip Pembangunan Berkelanjutan. Penyusunan Rekomendasi Perbaikan untuk Pengambilan Keputusan Kebijakan, Rencana dan Program. Informasi jenis usaha dan kegiatan yang telah melampaui daya dukung dan daya tampung Lingkungan Hidup tidak di perbolehkan lagi.
Variabel yang diamati:

1. Keanekaragaman hayati: variabilitas diantara semua makhluk hidup, interaksi ekosistem teresterial, pesisir dan lautan, ekosistem akuatik.

2. Limbah: sisa dari suatu usaha atau kegiatan.

3. Penanganan investasi oleh pihak sawasta: penanganan Investasi oleh professional.

4. Terganggunya keamanan dan kenyamanan: akibat yang ditimbulkan oleh suatu usaha atau kegiatan.

5. Peningkatan Kesejahteraan: berubahnya pendapatan ekonomi masyarakat dengan adanya satu usaha atau kegiatan.

6. Status lahan kawasan pariwisata: status kepemilikan lahan.

7. Kerusakan mangrove dan terumbu karang: seberapa besar rusaknya tempat berkembang biaknya biota laut yang berfungsi mencegah abrasi.

8. Ruang Terbuka Hijau: area memanjang yang penggunaanya bersifat terbuka, tempat tumbuh tanaman, baik yang tumbuh secara alamiah dan sengaja ditanam. Sesuai Peraturan Menteri Pekerjaan Umum No 5 Tahun 2008 menyebutkan proporsi Ruang Terbuka Hijau (RTH) perkotaan sebesar $30 \%$.

Analisis yang digunakan dalam penelitian ini menggunakan matriks dan bagan alir dengan metode semi detail yaitu penilaian berdasar data dan informasi yang lebih akurat dapat bersifat kuantitatif. Penelitian ini juga menggunakan analisis deskriptif yang bertujuan untuk membuat pendeskripsian secara sistematis, faktual, akurat mengenai fakta-fakta dan sifat-sifat daerah penelitian sesuai dengan permasalahan yaitu :

1. Mendapatkan data dan isu-isu strategis prioritas, peneliti melakukan Focus Group Discussion (FGD) dengan adanya partisipasi masyaaraakat di lokasi kawasan peruntukan pariwisata Kabupaten Bolaang Mongondow.

2. Mencari tahu dampak Program dari Rencana Tata Ruang Wilayah (RTRW) kawasan peruntukan Pariwisata di Kabupaten Bolaang Mongondow, peneliti melakukan interview kepada $\mathrm{Q}$ informan (informan kunci) yaitu Kepala SKPD terkait, Akademisi, Tokoh masyarakat, LSM dan Tokoh Pemuda yang berada di daerah sekitar Kawasan peruntukan Pariwisata Kabupaten Bolaang Mongondow.

3. Mitigasi dampak negatif dari Program peneliti melakukan interview kepada Q informan (informan kunci) yaitu Kepala SKPD terkait, Akademisi. 
Analisis Pembobotan/Skoring Dampak Rencana dan Program dengan Isu Pembangunan Berkelanjutan Kawasan Peruntukan Pariwisata di Kabupaten Bolaang Mongondow, dapat dilihat pada Tabel 1.

\begin{tabular}{|c|c|c|c|c|c|}
\hline \multirow{2}{*}{$\begin{array}{c}\text { Tabel } 1 . \\
\text { Program }\end{array}$} & \multicolumn{5}{|c|}{$\begin{array}{l}\text { Analisis Pembobotan / Skoring Dampak Program dengan Isu } \\
\text { Pembangunan Berkelanjutan Prioritas Kawasan Peruntukan } \\
\text { Pariwisata di Kabupaten Bolaang Mongondow. }\end{array}$} \\
\hline & $\begin{array}{c}\text { Keanekarag } \\
\text { aman } \\
\text { Hayati }\end{array}$ & $\underset{\text { ah }}{\operatorname{Limb}}$ & $\begin{array}{l}\text { Terganggunya } \\
\text { Keamanan } \\
\text { dan } \\
\text { kenyamanan }\end{array}$ & $\begin{array}{c}\text { Peningk } \\
\text { atan } \\
\text { Kesejaht } \\
\text { eraan }\end{array}$ & $\begin{array}{c}\text { Kerusaka } \\
\text { n } \\
\text { Mangrov } \\
\text { e dan } \\
\text { terumbu } \\
\text { karang }\end{array}$ \\
\hline $\begin{array}{l}\text { 1. Kawasan } \\
\text { peruntukan } \\
\text { pariwisata } \\
\text { Budaya : } \\
\text { Makam } \\
\text { Bogani di } \\
\text { Kec. Passi } \\
\text { Barat, Passi } \\
\text { Timur dan } \\
\text { Bilalang } \\
\end{array}$ & 0 & -1 & -1 & +1 & 0 \\
\hline $\begin{array}{l}\text { 2. Kawasan } \\
\text { perumtukan } \\
\text { Pariwisata }\end{array}$ & & & & & \\
\hline $\begin{array}{l}\text { Alam: } \\
\text { a. Taman } \\
\text { Nasional } \\
\text { BNWB }\end{array}$ & -1 & -1 & -1 & +1 & 0 \\
\hline $\begin{array}{l}\text { b. Air panas } \\
\text { Bakan }\end{array}$ & -1 & -1 & -1 & +1 & 0 \\
\hline $\begin{array}{l}\text { c. Pendakian } \\
\text { Gunung }\end{array}$ & -1 & -1 & -1 & +1 & 0 \\
\hline $\begin{array}{l}\text { Ambang } \\
\text { d. Pantai } \\
\text { Lolan }\end{array}$ & -1 & -1 & -1 & +1 & -1 \\
\hline $\begin{array}{l}\text { e. Air Terjun } \\
\text { Otam }\end{array}$ & -1 & -1 & -1 & +1 & 0 \\
\hline $\begin{array}{l}\text { f. Pantai } \\
\text { Tanjung } \\
\text { Ompu }\end{array}$ & -1 & -1 & -1 & +1 & -1 \\
\hline $\begin{array}{l}\text { g. Pulau } \\
\text { Molosing }\end{array}$ & -1 & -1 & -1 & +1 & -1 \\
\hline $\begin{array}{l}\text { h. Kawasan } \\
\text { Pulau Tiga }\end{array}$ & -1 & -1 & -1 & +1 & -1 \\
\hline
\end{tabular}

Keterangan : $\quad-1$ Ada keterkaitan dengan program dan isu pembangunan +1 Tidak ada keterkaitan dengan program dan isu pembangunan 0 Tidak ada hubungan (tidak bersinergi)

\section{HASIL DAN PEMBAHASAN}

\section{Gambaran Umum Kabupaten Bolaang Mongondow}

\section{Letak administrasi Kabupaten Bolaang Mongondow}

Secara astronomis, Kabupaten Bolaang Mongondow terletak $00^{\circ} 15^{\prime} 46^{\prime \prime}-01^{\circ} 15^{\prime} 38^{\prime \prime}$ Lintang Utara dan antara $123^{\circ} 07^{\prime} 26^{\prime \prime}-124^{\circ} 41^{\prime} 46^{\prime \prime}$ Bujur Timur. Berdasarkan posisi geografisnya, Kabupaten Bolaang Mongondow merupakan salah satu Kabupaten yang terletak di Provinsi Sulawesi Utara dan memiliki batas- batas: Utara-Laut Sulawesi, Selatan-Kabupaten Bolaang Mongondow
Selatan dan Kabupaten Bolaang Mongondow Timur, Barat-Kabupaten Bolaang Mongondow Utara dan Timur-Kabupaten Minahasa Selatan dan Kabupaten Minahasa Tenggara. Kabupaten Bolaang Mongondow secara administratif terbagi kedalam 15 kecamatan dan 200 Desa/Kelurahan. Luas keseluruhannya mencapai $3.517,47 \mathrm{Km} 2$. Kecamatan Sang Tombolang merupakan kecamatan terluas yaitu dengan luas wilayah mencapai 776,31 $\mathrm{Km} 2$ atau 22,14 persen dari total wilayah Bolaang Mongondow. Akhir tahun 2016, wilayah administrasi Provinsi Bolaang Mongondow terdiri dari 15 kecamatan, dengan luas masing-masing kabupaten/kota, yaitu: Dumoga Barat (375,44 Km2), Dumoga Tengah (375,44 Km2), Dumoga Utara (539,93 Km2), Lolayan (297,00 Km2), Passi Barat (95,46 Km2), Passi Timur (86,35 Km2), Bilalang $(60,93 \mathrm{Km} 2)$, Poigar $(322,84 \mathrm{Km} 2)$, Bolaang (148,03 Km2), Bolaang Timur (65,20 Km2), Lolak (374,54 Km2), Sangtombolang (776,31 Km2).

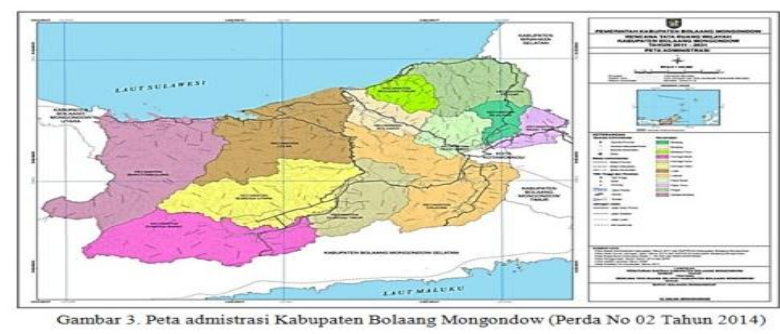

\section{Rencana Tata Ruang Wilayah (RTRW) Kabupaten Bolaang Mongondow Kawasan Peruntukan Pariwisata}

Penataan ruang adalah suatu sistem proses perencanaan tata ruang, pemanfaatan ruang dan pengendalian pemanfaatan ruang.

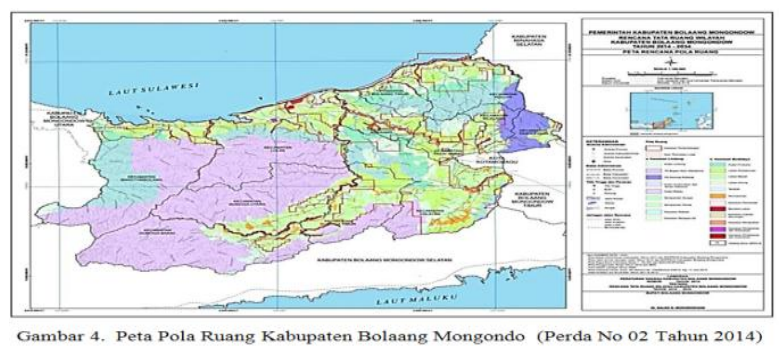

\section{Tujuan Penataan Ruang}

Tujuan penataan ruang Kabupaten Bolaang Mongondow adalah mewujudkan ruang wilayah Bolaang Mongondow yang aman, nyaman, produktif dan berkelanjutan sebagai lumbung pangan nasional yang lestari dan daerah tujuan ekowisata (Perda No 4 Tahun 2014) secara geografis terletak pada posisi $123^{0}-124^{0}$ BT dan $0^{0} 30^{\prime}-1^{0}$ 0 ' LU serta berbatasan dengan wilayah lain di Provinsi Sulawesi Utara sebagai berikut: 
a. Sebelah Utara berbatasan dengan Laut Sulawesi

b. Sebelah Timur berbatasan dengan Kota Kotamobagu, Kabupaten Minahasa Selatan dan Kabupaten Bolaang Mongondow Timur

c. Sebelah Selatan berbatasan dengan Kabupaten Bolaang Mongondow Selatan

d. Sebelah Barat berbatasan dengan Kabupaten Bolaang Mongondow Utara dan Kabupaten Bolaang Mongondow Selatan.

\section{Indikator Program RTRW}

Indikasi Program RTRW Peruntukkan Pariwisata Kabupaten Bolaang Mongondow meliputi tahapan Penyusunan Masterplan Pariwisata/Rencana Induk Pariwisata Daerah (RIPDA) selanjutnya penyediaan Infrastruktur pendukung pariwisata, promosi wisata melalui berbagai media, perencanaan penyelenggaraan event serta pelestarian situs-situs budaya Bolaang Mongondow yang tersebar di wilayah Bolaang mongondow dengan garis koordinasi dan pengawasan dari Dinas Pariwisata Kabupaten Bolaang Mongondow.

Dalam Perda No 2 Tahun 2014, Kawasan Peruntukan pariwisata Kabupaten Bolaang Mongondow adalah: Kawasan peruntukan pariwisata terdiri kawasan peruntukan pariwisata budaya dan kawasan peruntukan pariwisata alam.

a. Kawasan peruntukan pariwisata budaya berupa Makam Bogani di Kecamatan Passi Barat, Kecamatan Passi Timur, Kecamatan Bilalang dan seluruh kecamatan yang memiliki situs-situs sejarah.

b. Kawasan peruntukan pariwisata alam meliputi: wisata petualang dan ilmu pengetahuan di Taman Nasional Bogani Nani Wartabone, tempat pemandian air panas Bakan, wisata pendakian Gunung Ambang, pantai Lolan, air terjun Otam dan tempat pemandian di pantai Tanjung Ompu, Pulau Molosing serta Kawasan Pulau Tiga.

\section{Indentifikasi Isu-isu Dampak Penting/Strategis bidang Pariwisata di Kabupaten Bolaang Mongondow}

Tindakan Pengelolaan Lingkungan di lakukan secara holistik (menyeluruh) di mulai dari tahap perencanaan sampai pada tahap pembangunan agar prinsip- prinsip Pembangunan Berkelanjutan dapat di terapkan. Kajian Lingkungan Hidup Strategis (KLHS) di laksanakan pada tahap perencanaan suatu program untuk meminimalisir dan memitgasi dampak resiko terhadap lingkungan.

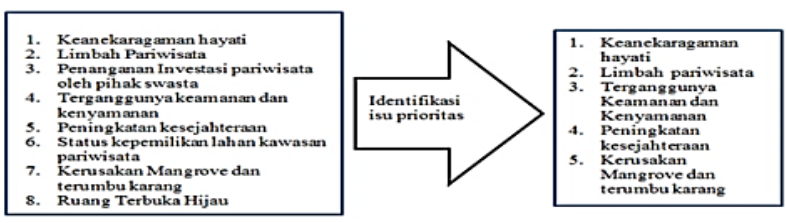

Gambar 5. Hasil identifikasi isu strategi prioritas pembangunan berkelanjutan

Isu-isu dampak penting/strategis kawasan peruntukan pariwisata di Kabupaten Bolaang Mongondow di peroleh melalui pelaksanaan Focus Group Disscussion (FGD) dan wawancara secara mendalam dengan Stakeholder terkait yaitu Kepala SKPD terkait, Tokoh masyarakat, tokoh agama, tokoh pemuda, akademisi dan masyarakat.

Isu-isu prioritas Pembangunan Berkelanjutan yang teridentifikasi di Kabupaten Bolaang Mongondow adalah :

1. Keanekaragaman hayati

2. Limbah

3. Penanganan Investasi pariwisata oleh pihak swasta

4. Terganggunya keamanan dan kenyamanan

5. Peningkatan kesejahteraan

6. Status kepemilikan lahan kawasan pariwisata

7. Kerusakan mangrove dan terumbu karang

8. Ruang Terbuka Hijau

\begin{tabular}{|c|c|c|c|c|c|c|c|}
\hline 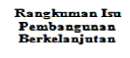 & 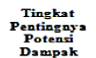 & $\begin{array}{c}\text { Telah } \\
\text { Karrakterist } \\
\text { ik wilay ah }\end{array}$ & 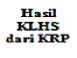 & $\begin{array}{l}\text { Mnatan } \\
\text { KPPIH }\end{array}$ & $\begin{array}{l}\text { Keterk } \\
\text { sitan } \\
\text { dengan } \\
\text { mastan }\end{array}$ & 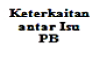 & Total \\
\hline Keanekaraga- & $\begin{array}{l}40 \% \\
8=3,2\end{array}$ & $\begin{array}{l}20 \% \\
7=1,4\end{array}$ & $\begin{array}{l}10 \% \\
7=0,7\end{array}$ & $\begin{array}{l}10 \% \\
7=0,7\end{array}$ & $\begin{array}{l}10 \% \\
7=0,7\end{array}$ & $\begin{array}{l}10 \% \\
7=0,7\end{array}$ & $43=7,4$ \\
\hline $\begin{array}{l}\text { man Hayati } \\
\text { Limbah }\end{array}$ & $s=3,2$ & $6=1,2$ & $7=0,7$ & $s=0, s$ & $7=0,7$ & $7=0,7$ & $43=7,3$ \\
\hline $\begin{array}{l}\text { Pariwisata } \\
\text { Penanganan } \\
\text { Investasi } \\
\text { oleh pihak }\end{array}$ & $2=0,8$ & $3=0,6$ & $5=0,5$ & $5=0,5$ & $s=0,5$ & $3=0,3$ & $23=2,4$ \\
\hline $\begin{array}{l}\text { swas sta } \\
\text { Tergangu- } \\
\text { nya } \\
\text { Keamananan } \\
\text { dan }\end{array}$ & $7=2,8$ & $7=1,4$ & $s=0, s$ & $7=0,7$ & $7=0,7$ & $7=0,7$ & $43=7,1$ \\
\hline $\begin{array}{l}\text { kenyamanan } \\
\text { Peningkeatan } \\
\text { Kesejahtera- }\end{array}$ & $s=3,2$ & $7=1,4$ & $7=0,7$ & $7=0,7$ & $7=0,7$ & $7=0,7$ & $43=7,4$ \\
\hline $\begin{array}{l}\text { an } \\
\text { Status }\end{array}$ & $5=2$ & $2=0,4$ & $5=0,5$ & $3=0,3$ & $5=0,5$ & $5=0,5$ & $25=4,2$ \\
\hline $\begin{array}{l}\text { lahan } \\
\text { Kerusakan } \\
\text { mangrove } \\
\text { dan terumbu }\end{array}$ & $s=3,2$ & $s=1,6$ & $7=0,7$ & $s=0, s$ & $7=0,7$ & $7=0.7$ & $45=7,7$ \\
\hline $\begin{array}{l}\text { karang } \\
\text { Ruang } \\
\text { Terbukka } \\
\text { Hijau }\end{array}$ & $2=0, s$ & $s=1$ & $3=0,3$ & $s=0,5$ & $3=0,3$ & $s=0,3$ & $23=3,2$ \\
\hline
\end{tabular}

Keterangan :

$\begin{array}{ll}1 \mathrm{~s} \mathrm{~s} / \mathrm{d} 2 & \text { Sangat rendah } \\ 3 \mathrm{~s} / \mathrm{d} 4 & \text { Rendah } \\ 5 \mathrm{~s} / \mathrm{d} 6 & \text { Sedang } \\ 7 \mathrm{~s} / \mathrm{d} 8 & \text { Tinggi }\end{array}$

Isu pembangunan berkelanjutan di Kabupaten Bolaang Mongondow yang di peroleh ada 5 (lima) isu prioritas paling strategis yang diidentifikasi dengan memperhatikan unsur-unsur lingkungan hidup meliputi karakteristik wilayah, tingkat pentingnya potensi dampak, keterkaitan antar isu strategis Pembangunan Berkelanjutan, keterkaitan dengan KRP, serta muatan Rencana Perlindungan dan Pengelolaan Lingkungan Hidup adalah: 
1. Keanekaragaman hayati

2. Limbah Pariwisata

3. Terganggunya keamanan dan kenyamanan

4. Peningkatan Kesejahteraan

5. Kerusakan mangrove dan terumbu karang

\section{Keanekaragaman hayati}

Hasil Penelitian Kawasan peruntukan pariwisata di Kabupaten Bolaang Mongondow memiliki beragam keanekaragaman hayati seperti berbagai flora (beragam plasma nutfah) dan Fauna seperti burung maleo, burung manguni dan berbagai jenis species fauna di Taman Nasinal Bogani Nani Wartabone yang di lestarikan, beragam biota Laut (Terumbu karang, species ikan, bioma dan padang lamun) di sekitar kawasan wisata pantai utara.

Pengembangan kawasan wisata pantai akan mengakibatkan rusaknya keanekaragaman hayati dengan adanya program pembangunan fasilitas penunjang pariwisata seperti jalan/transportasi, hotel/ cottage/penginapan, rumah makan, rest Area, parkiran dan ruang publik. Rusaknya keanekaragaman hayati di sekitar kawasan wisata pantai lolan, tanjung ompu, pulau molosing dan pasir putih akan terjadi jika tidak adanya kesadaran dari pelaku pariwisata untuk melaksanakan kegiatan wisata tanpa merusak keanekaragaaman hayati di sekitar kawasan.

Pengembangan kawasan pariwisata di Taman Nasional Bogani Nani Wartabone Desa Tambun Pinonobatuan Timur Kecamatan Dumoga Timur berupa penangkaran Burung Maleo. Satwa liar yang hampir punah dengan ciri-ciri khusus ini sengaja di tangkar agar tetap lestari mengingat burung maleo ini tergolong species hampir punah.

\section{Limbah}

Hasil penelitian di beberapa kawasan peruntukan pariwisata terdapat keluhan masyarakat tentang bagaimana penanganan limbah dari kegiatan pariwisata yang dapat menyebabkan pencemaran lingkungan.

Hasil turun lapangan penelitian di kawasan peruntukan pariwisata pasir putih dan pulau tiga belum terdapat tempat-tempat pembuangan sampah dan papan informasi tentang limbah pariwisata, sehingga di khawatirkan dengan adanya program pengembangan dan pembangunan fasilitas pariwisata akan menyebabkan pencemaran lingkungan. Pembuangan sampah padat di sekitar perairan pulau tiga di khawatirkan akan menyebabkan pencemaran air dan merusak biota laut.

Perasaan khawatir warga sekitar kawasan ketika kawasan wisata di buka adalah pencemaran limbah padat dan cair akan terjadi di luar batas kontrol pemerintah sehingga limbah tersebut membawa dampak negatif kepada masyarakat sekitar kawasan seperti terkenanya penyakit kulit dan pernapasan. Untuk itu masyarakat sangat mengharapkan pemerintah dapat melakukan perencanaan pengembangan wisata dengan mempertimbangkan faktor lingkungan.

\section{Terganggunya keamanan dan kenyamanan}

Faktor keamanan merupakan salah satu unsur penting dalam pelaksanaan suatu kegiatan guna terciptanya rasa aman dan nyaman termasuk kegiatan pengembangan pariwisata. Seperti yang terjadi di beberapa kawasan pariwisata, hasil wawancara beberapa tokoh masyarakat dan masyarakat mengeluhkan mereka harus menangani beberapa kasus perkelahian di kawasan wisata namun Pemerintah Daerah Kabupaten Bolaang Mongondow tidak pernah melibatkan masyarakat dalam pengelolaan wisata tersebut.

Kepala Dinas Pariwisata Kabupaten Bolaang Mongondow Dra. Hj. Ulfa Paputungan, MAP mengatakan memang untuk saat ini pemerintah belum menganggarkan satuan keamanan di kawasan pariwisata namun masih di prioritaskan pada kasus kecelakaan yang sering terjadi di kawasan pariwisata pada saat hari-hari libur karena jumlah pengunjung meningkat dengan melibatkan personil Badan Penaggulangan Bencana Daerah. Beberapa kasus kecelakaan wisata pantai sering terjadi yaitu pengunjung di bawa arus atau tenggelam.

Hasil wawancara dengan Badan Penanggulangan Bencana Daerah Kabupaten Bolaang Mongondow Ir. Channy Wayong, MSi mengatakan dalam hal menunjang program pemerintah di bidang pariwisata dengan tujuan menciptakan rasa nyaman untuk pelaku wisata, BPBD Bolaang Mongondow telah melakukan program patroli pantai pada saat hari libur yang di fokuskan di koridor pantai utara (pantai lolan, pantai bungin dan pulau tiga) yaitu pada daerah rentan bencana tsunami, abrasi dan gelombang pantai. Selain itu BPBD telah melakukan upaya perspentif yaitu dengan pemasangan papan informasi siaga di tempat wisata, sosialisasi penanganan darurat dan evalusai SAR, rekrut relawan untuk kegiatan bencana, pembuatan tanggul pengamanan pantai.

\section{Peningkatan Kesejahteraan}

Hasil wawancara dengan tokoh masyarakat, tokoh adat, tokoh agama, masyarakat dan akademisi serta pimpinan SKPD terkait, masyarakat sekitar kawasan sangat mengharapkan dengan adanya program pengembangan pariwisata di Kabupaten Bolaang Mongondow akan meningkatan kesejahteraan. Masyarakat berharap pemerintah melibatkan dalam kegiatan pariwisata seperti perekrutan tenaga kerja perhotelan, perekrutan tenaga kerja restaurant, 
perekrutan tenaga kerja penagihan retribusi, perekrutan tenaga kerja kebersihan dan keamanan serta peluang usaha lainnya (kuliner dan kerajinan setempat) di sekitar kawasan wisata.

\section{Kerusakan Mangrove dan terumbu karang}

Hasil Focus Group Disscusiion (FGD) di desa Pasir Putih Kecamatan Sang Tombolang, beberapa tokoh masyarakat mengatakan di kawasan wisata pulau tiga dan pasir putih telah terjadi kerusakan mangrove dan terumbu karang. Kawasan Pulau Tiga yang mempunyai luas kurang lebih 14 Ha memiliki sumber daya alam yang kaya seperti hutan, pasir putih, mangrove dan terumbu karang. Namun saat ini telah terjadi pengrusakan di sebabkan ulah manusia yang mengambil ikan secara tidak teratur dan merusak terumbu karang di sekitar lokasi pulau tiga dan pasir putih.

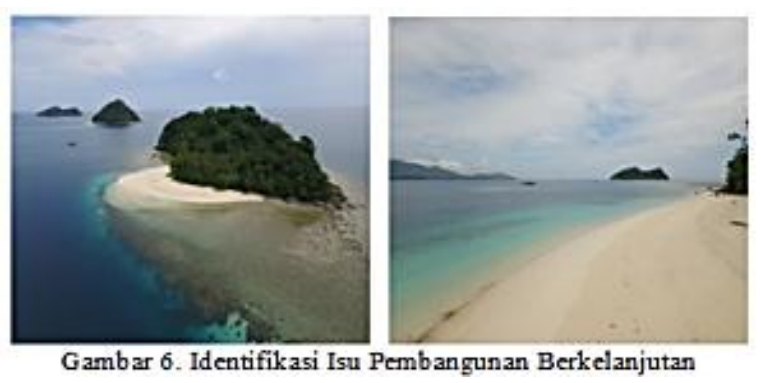

Sumber dari Dinas Perikanan dan Kelautan Kabupaten Bolaang Mongondow melalui kepala bidang Mohamad Ridel Syukur mengatakan internal dinas Perikanan dan Kelautan dalam menunjang Program Pemerintah bidang pariwisata telah membuat kawasan konservasi mangrove dan terumbu karang. Rehabilitasi mangrove telah di mulai dari Tahun 2012 di lokasi sekitar Kawasan wisata pulau Tiga Desa Pasir Putih Kecamatan Sang Tombolang dan hasilnya telah dapat di manfaatkan.

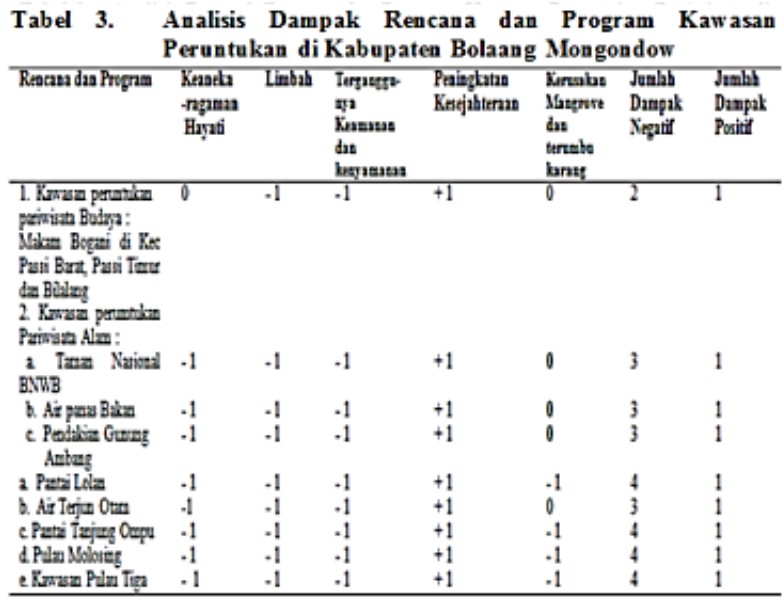

Hasil analisis dampak negatif rencana dan program pengembangan pengelolaan kawasan peruntukan pariwisata di Kabupaten Bolaang Mongondow adalah angka negatif tertinggi.

\section{Telaahan Dampak Pelaksanaan Program dan Mitigasi}

Telaahan dampak pelaksanaan program dan mitigasi dampak negative.

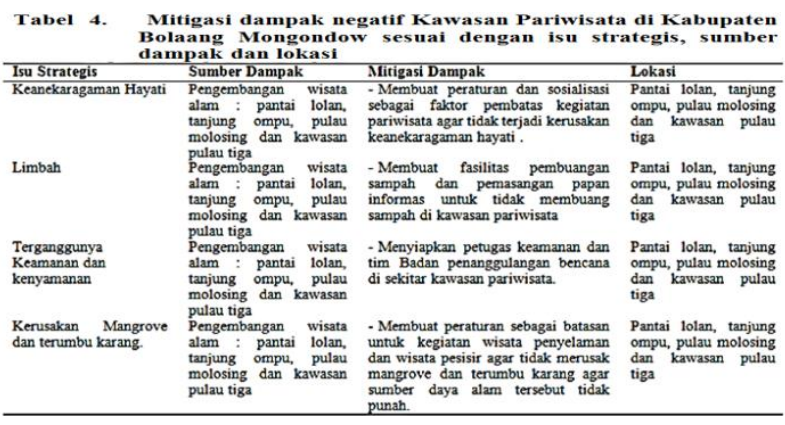

\section{KESIMPULAN DAN SARAN}

\section{Kesimpulan}

1. Identifikasi Isu-isu strategis kawasan peruntukan pariwisata di Kabupaten Bolaang Mongondow yaitu:

a. Keanekaragaman hayati

b. Limbah Pariwisata

c. Penaganan Investasi pariwisata oleh pihak swasta

d. Terganggunya keamanan dan kenyamanan

e. Peningkatan kesejahteraan

f. Status kepemilikan lahan kawasan pariwisata

g. Kerusakan Mangrove dan terumbu karang

h. Ruang Terbuka Hijau

2. Isu-isu prioritas pembangunan berkelanjutan kawasan peruntukan pariwisata di Kabupaten

Bolaang Mongondow :

a. Keanekaragaman hayati

b. Limbah

c. Terganggunya keamanan dan kenyamanan

d. Peningkatan kesejahteraan

e. Kerusakan mangrove dan terumbu karang

3. Mitigasi meminimalkan dampak negatif adalah: Membuat peraturan daerah tentang perlindungan keanekaragaman hayati di sekitar kawasan pariwisata, menyiapkan fasilitas penampungan dan pengolahan limbah padat dan cair dari kegiatan pariwisata, menyiapkan petugas keamanan dan tim badan penanggulangan bencana di sekitar kawasan pariwisata, membuat peraturan daerah 
sebagai faktor pembatas kegiatan wisata penyelaman dan wisata pesisir untuk meminimalisir kerusakan mangrove dan terumbu karang.

\section{Saran}

1. Pemerintah Kabupaten Bolaang Mongondow harus meningkatkan kapasitas sumber daya manusia, aparatur sehingga kinerja dalam pengendalian pembangunan berkelanjutan dapat diterapkan sesuai dengan Rencana Tata Ruang Wilayah.

2. Pemerintah Kabupaten Bolaang Mongondow harus menjalankan secara tegas Peraturan Daerah No. 2 Tahun 2014 tentang Rencana Tata Ruang Wilayah Kabupaten Bolaang Mongondow (Tahun 2014-2034)

3. Sebagai daerah yang kaya akan sumber daya alam, pariwisata pantai yang berada pada jalur trans Sulawesi, rencana dan program pembangunan fasilitas pariwisata yang mendukung serta kemauan masyarakat setempat untuk pengembangan pariwisata, kawasan peruntukan pariwisata koridor pantai utara di Kabupaten Bolaang Mongondow dapat dijadikan Kawasan Ekonomi Khusus (KEK) pariwisata.

\section{DAFTAR PUSTAKA}

Asdak, C., 2012. Kajian Lingkungan Hidup Strategis (KLHS) Jalan menuju Pembangunan Berkelanjutan. Gajah Mada University.

Badan Pusat Statistik Kabupaten Bolaang Mongondow. 2016. Bolaang Mongondow dalam Angka Tahun 2015.

Cahyaningrum,D., 2013. Penelitian Pariwisata, Studi Komparasi Potensi Desa Wisata Sari Bunhayu dalam satuan Kawasan Wisata Ciater di kabupaten Subang. Universitas Pendidikan Indonesia.

Damanhuri, H., 2003. Jurnal Terumbu Karang Kita. Pusat Kajian Mangrove dan Kawasan Pesisir. Universitas Bung Hatta Padang.

Dinas Pariwisata dan Kebudayaan Kabupaten Bolaang Mongondow. 2016. Destinasi Pariwisata Kabupaten Bolaang Mongondow.

Dinas Perikanan dan Kelautan Kab Bolaang Mongondow. 2016. Laporan Keanekaragaman Hayati di Kabupaten Bolaang Mongondow.

Draft Peraturan Menteri Lingkungan Hidup dan Kehutanan Republik Indonesia tentang Tata Cara Pengkajian Pengaruh Kebijakan, Rencana dan/atau Program terhadap Kondisi Lingkungan.
Fungsi dan peranan Hutan Mangrove dalam ekosistem pesisir BPSPL Denpasar. Balai pengelolaan Sumberdaya persisir dan laut Denpasar.

Kalalo, F. P., 2016. Hukum lingkungan dan kebijakan pertanahan di wilayah pesisir.

Kementerian Lingkungan Hidup. 2010. Kajian Lingkungan Hidup Startegis Sebagai Instrumen Pembangunan Berkelanjutan. Universitas Gajah Mada. Asisten Deputi Kajian Kebijakan Wilayah dan Sektor.

KLHS Kabupaten Buton Tengah. 2015. Penyusunan Rencana Induk Pengembangan Pariwisata Daerah Kabupaten Buton Tengah 2015-2025.

Koesrijanti, A. Wijayanti . Adhiwibowo, S. Nurlambang, T dan Asdak, C. 2008. Kajian Lingkungan Hidup Strategis terobosan Dalam Pengelolaan Lingkungan Hidup. Deputi Bidang Tata Lingkungan Kementerian Negara Lingkungan Hidup Republik Indonesia.

Koesrijanti, A., L. Adhiwibowo, S dan Nurlambang, T. 2000. Buku Pegangan Kajian Lingkungan Hidup Strategis. Deputi Bidang Tata Lingkungan Kementrian Negara Lingkungan Hidup Republik Indonesia.

Mulyana Bedi, 2010. Pengembangan Kota Bogor sebagai Destinasi Pariwisata International. Bogor City Tourism supply demand development destination. Volume 13. (Di Unduh Tanggal 17 Desember 2017, pukul 09:00 Wit)

Penerapan KLHS di Kebijakan Tata Ruang sebagai solusi masalah Lingkungan Hidup di Daerah. 2015. Kementerian Lingkungan Hidup Republik Indonesia. ( Di Unduh Tanggal 20 Mei 2017, Pukul 18:05 Wita)

Pentingnya Penerapan KLHS di Indonesia. MenLH.go.id. (Di unduh Tanggal 18 Mei 2017, Pukul: 15:00 Wita)

Peraturan Daerah Nomor 2 Tahun 2014 Tentang Rencana Tata Ruang Wilayah (RTRW) Kabupaten Bolaang Mongondow 2014-2034.

Peraturan Menteri Dalam Negeri No 67 Tahun 2012 Tentang Pedoman Pelaksanaan Kajian Lingkungan Hidup Strategis dalam penyusunan atau Evaluasi Rencana Pembangunan Daerah.

Peraturan Menteri No 9 Tahun 2011 tentang Pedoman Umum tentang Kajian Lingkungan Strategis.

Peraturan Menteri Pekerjaan Umum No 05/PRT/M/2008 tentang Pedoman Penyediaan dan Pemanfaatan RTH di Kawasan Perkotaan.

Peraturan Pemerintah Republik Indonesia Nomor 46 Tahun 2016 Tentang Tata Cara Penyelenggaraan Kajian Lingkungan Hidup Strategis. 
Peraturan Pemerintah Republik Indonesia Nomor 50 Tahun 2011 Tentang Rencana Induk Pembangunan Kepariwisataan Nasional.

Peraturan Pemerintah Republik Indonesia Nomor 63 Tahun 2014 Tentang Pengawasan dan pengendalian Pariwisata.

Prinsip-prinsip Pembangunan Berkelanjutan. www.radarplanologi.com $>$ tinjauanteori $(\mathrm{Di}$ Unduh tanggal 22 Mei 2017, pukul 13.00 Wita)

Resa A. M., 2016. Dampak Pembangunan Pariwisata terhadap Lingkungan. Studio riau. com (Di Unduh Tanggal 5 Desember 2017, pukul 17.00 Wit)

Saputri T. E., 2012. Pengertian Pariwisata, Kepariwisataan dan perjalanan wisata. Blogspot. co. id (Di Undul Tanggal 8 Desember 2017, pukul 19.00 Wit)

Satar, M., 2012. Kajian Lingkungan Hidup Strategis (KLHS) dalam penataan Ruang (memasukkan aspek konservasi). Geography Regional Planning. Musnanda. com (Di Unduh Tanggal 14 Desember 2017, pukul 20:00 Wit)
Setyabudi B., 2008. Kajian Lingkungan Hidup dalam Penataan Ruang. Asisten Deputi Urusan Lingkungan Kementerian Lingkungan Hidup. Jakarta.

Undang-Undang Republik Indonesia Nomor 5 Tahun 1994 Tentang Pengesahan United Nations Convention on Biological Diversity-Konversi Perserikatan BangsaBangsa mengenai Keanekaragaman Hayati.

Undang-Undang Republik Indonesia Nomor 10 tahun 2009 Tentang Kepariwisataan.

Undang-Undang Republik Indonesia Nomor 26 Tahun 2007 Tentang Penataan Ruang.

Undang-Undang Republik Indonesia Nomor 32 Tahun 2009 Tentang Perlindungan dan Pengelolaan Lingkungan Hidup.

Widyastuti. R. A., 2010. Pengembangan Pariwisata yang berorientasi pada pelestarian fungsi lingkungan. Fak Hukum. Universitas Katolik St. Thomas Sumatera Utara Medan. (Diunduh tanggal 17 Desember 2017 pukul 20.00 WIT). 